\title{
Same but Different: A Comparison of Players' Perceptions and Motivational Factors in Two Commercially Available AR
}

\section{Games}

\section{Anna Schlomann ${ }^{1,2}$ (1) $\cdot$ Peter Rasche ${ }^{3}$ (i)}

Received: 3 June 2020 / Accepted: 16 September 2020 / Published online: 3 October 2020

(c) The Author(s) 2020

\begin{abstract}
In 2019, the Harry Potter-themed augmented reality (AR) game Wizards Unite was released, one which employed the same game mechanics as Pokémon Go. In order to explore the similarities and differences in players' perceptions, motivations to play, and missing functions in Wizards Unite and Pokémon Go, we conducted a web-based survey which targeted active players of Wizards Unite 14 weeks after its release. The results are compared to a survey applying the same methodology and questions directed at active players of Pokémon Go. An important reason why many players started playing Wizards Unite was that they were already Harry Potter fans. For Wizards Unite players the motivation stemming from public attention was lower compared to that for Pokémon Go players. The main motivating factors drawing players to these games include fun, curiosity, and being physically active. The AR function was not mentioned as a motivating factor for either game. The aspect of players being able to collect and complete the game was more of a motivation for playing Pokémon Go. Although the game mechanisms are similar, we identified specific differences in the motivational factors of the two games. The main difference is the misfit between the general game story with hunting and collecting within the Harry Potter universe. Nevertheless, the theme of the game and its background story can be important long-term motivating factors of Wizards Unite. The findings in this paper provide insights into how one can create AR games that meet players' needs.
\end{abstract}

Keywords Smartphone $\cdot$ Games $\cdot$ Augmented reality (AR) $\cdot$ Niantics $\cdot$ Harry Potter

Anna Schlomann

schlomann@nar.uni-heidelberg.de

1 Network Aging Research, Heidelberg University, Bergheimer Straße 20, 69115 Heidelberg, Germany

2 Mixed Methods Research, Heidelberg University of Education, Heidelberg, Germany

3 Institut für Arbeitswissenschaft der RWTH Aachen University, Aachen, Germany 


\section{Abbreviation}

AR Augmented reality

\section{Introduction}

Augmented reality (AR) game concepts have gained importance in recent years (Hamari et al. 2019). A significant driver for this development is the evolution of smartphones and tablets, and the success of the AR game Pokémon Go when millions of people around the world started to play this game in 2016 (Paavilainen et al. 2017). Encouraged by the high numbers of players and the worldwide success of Pokémon Go, location-based gaming concepts including AR have also become the focus of academic research. Researchers have shown the positive effects that playing such games can have on physical activity (e.g. Althoff et al. 2016; LeBlanc and Chaput 2017; Hino et al. 2019; Howe et al. 2016) as well as positive effects on social and psychological outcomes (Ewell et al. 2020). In addition, researchers have explored various problems and risks which players might encounter (e.g. Serino et al. 2016; Ayers et al. 2016).

In 2019, the Harry Potter-themed AR game Wizards Unite was released (Warner Bros. Entertainment 2020). Both games, Pokémon Go and Wizards Unite, were codeveloped by Niantic and have similar game mechanisms as well as infrastructure, in that the main user interface is based on a real-world map and the main gameplay includes navigation within real environments (Laato et al. 2020). Known as 'urban exergames', both games run on smartphones and make use of the built-in sensors on mobile devices (Knöll et al. 2014). A geocaching concept is combined with AR mechanics, and players explore their real-world neighborhoods in search of different objects. In Pokémon Go, players seek, hunt, and collect a variety of different fictional creatures called Pokémons (ref. to Pocket Monsters). The players in Wizards Unite seek and collect Dark Arts or Magizoology items, also known as 'Foundables', and they follow 'traces' (Laato et al. 2020). The players visit points of interest that have a distinct meanings in the game (e.g. Pokéstops and Gyms in Pokémon Go, and Greenhouses and Fortresses in Wizards Unite). The implemented AR feature embeds two-dimensionally animated objects in real-world images that are captured by the mobile phone camera (Laato et al. 2020). However, both games also offer a virtual game mode whereby the mobile phone camera is deactivated, and the objects are shown in a virtual environment only (Rasche et al. 2017; Warner Bros. Entertainment 2020).

Another similarity between the two games is that they are both based on a strong and well-known franchise, each with roots dating back to the 1990s. The Pokémon brand has been merchandized in the form of video games, card games, movies, television series, and comic books. Wizards Unite is based on the world of wizardry that is found in the Harry Potter novels by J.K. Rowling. The first volume was published in 1997, followed by six other novels, eight movies, theatre plays, among other spin-offs. Taken together, Harry Potter is one of the most famous book series of all time (Wizarding World 2020). However, it should be mentioned that players might perceive these two games differently as they are 
well-known franchises. The success of the Harry Potter brand stems mostly from the novels and movies, while people often associate the Pokémon brand with video games. The popularity of these different media affect players' expectations of games based on these brands. These differences might also explain why Pokémon Go gained more attention than Wizards Unite when it was released. For example, there were 15 million downloads of the game and earnings of US\$12 million for Wizards Unite in its first month of release, compared to 182 million downloads and US\$300 million earnings for Pokémon Go in the same period (Handrahan 2019).

From our understanding, there is limited knowledge on the perceptions and motivations of active players of the two games. Other researchers have compared the effects that playing such games have on physical activity of players and their ways of playing (e.g. McLaughlin et al. 2019; Laato et al. 2020). However, Wizards Unite and Pokémon Go have not been compared systematically in an effort to better understand similarities and differences of players' perceptions and motivation. In fact, Wizards Unite has received less attention from the public and academia than Pokémon Go. It is also necessary to explore the players' perspectives in order to develop more general implications for future AR-based games, and to focus on the factors that might motivate people into playing future games. Knowledge of the perspectives of players enables designers to recognize demographic characteristics, as well as learn how satisfied players are with their games, the motivations for playing, and significant missing features in the games.

Due to the similarity of Pokémon Go and Wizards Unite as game concepts, it is rational to compare the motivational factors between the two groups of players. For example, it is worth questioning whether users of each respective game are more attracted by game theme (i.e. Harry Potter vs. Pokémon) or more attracted by some technological aspect of the game (e.g. AR). It is also possible to derive implications for the design of future AR games by understanding the differences and similarities between the two groups of players.

The aim of this paper is to explore these aspects of the two commercially available AR games, Wizards Unite and Pokémon Go. While much research has already focused on Pokémon Go, our focus is particularly on Wizards Unite. (Pokémon Go still serves as a reference in our research.) Our research questions are as follows:

1. Which demographic characteristics can be used to describe players of Wizards Unite, and are there differences between them and players of Pokémon Go?

2. What are the typical ways of playing Wizards Unite, and are there differences compared to Pokémon Go?

3. What are relevant motivational factors which induce players to start playing Wizards Unite, and how do they differ from those motivating Pokémon Go players?

4. What are the relevant motivational factors for continuing to play Wizards Unite, and how do they differ from Pokémon Go?

5. What are relevant missing functions in Wizards Unite, and how do these differ from Pokémon Go? 


\section{Method}

\subsection{Design}

An open, self-selected web-based survey was designed and used to collect data from active players of Wizards Unite. The survey was written in German, and based on a previous survey of Pokémon Go players (Rasche et al. 2017). Both surveys were provided for German-speaking internet users. A web-based survey is a suitable method for targeting individuals with specific characteristics or interests, especially potential game users, without any limitations in terms of physical space or time (Best and Krueger 2004; Topolovec-Vranic and Natarajan 2016). In order to make comparisons between players of Wizards Unite and those playing Pokémon Go, the results of the web-based survey are compared to those of the survey conducted among Pokémon Go players in 2016 (Rasche et al. 2017). All measures in the Wizards Unite survey were developed with reference to the prior survey on Pokémon Go (Rasche et al. 2017) to allow the best possible comparison between the two games.

\subsubsection{Measuring Game Status and Usage Behavior}

The participants answered questions about their use of the game since installation. For example, they reported the duration of use (in months), their level in the game, the duration of use in the first week after installation (in hours), and the duration of use in the week before the survey (in hours). To gain more insights into the ways of playing, they were also asked to report in-app purchases (yes/no, and money paid (in euros)), the game mode they preferred (AR-environment only, virtual environment only, depending on specific situation), and their personal reasons for the game mode (seven reasons against which they ticked 'yes' or 'no'). Furthermore, they were asked whether they would recommend the game to someone else (10-point scale: $1=$ very unlikely, $10=$ very likely). Being a Harry Potter fan independent of the game Wizards Unite was measured using a five-point scale $(1=$ not a fan all, $5=$ absolute fan).

\subsubsection{Measuring Motivation}

The participants also answered questions concerning motivational aspects which induced them into playing Wizards Unite. These questions referred to the initial motivation (which compelled them to start playing the game), motivation to continue playing, and missing elements in the game. As regards motivation to start playing, seven possible reasons were presented (yes/no). In order to gain information about the motivations for continuing to play the game, we asked players to indicate their level of desire to reach the next level (10-point scale: $1=$ did not motivate at all, $10=$ highly motivated). Via an open-ended question, we asked the players to cite other specific reasons which motivated them to continue playing. The open questions were coded for analysis, and the coding was done by one researcher and verified by a 
second researcher. The researchers discussed any discrepancies and found an agreement. To gain information about missing functions, eight specific aspects (yes/no) were asked of the participants. All questions on motivation and missing elements provided a field for open entries to allow the participants to report further aspects that were relevant to them. However, this open field was only used to a minimal extent, and only the answers to the pre-defined categories are reported here.

\subsection{Data Collection}

Data was collected between October 19 and November 3, 2019, 14 weeks after the release of Wizards Unite. The questionnaire was programmed and made available on a website that used the SoSci-Survey software (Leiner 2014). All participants were informed about the duration of the survey, data storage, and the principal investigators. Each participant decided to take part in this survey voluntarily by following a link to the survey, and no incentives were offered for participation. All measurements were harmonized with those of a survey on Pokémon Go 14 weeks after its release in 2016 (see Rasche et al. 2017) to allow for comparative analyses in the best way possible. The wording and technical functionality of the survey were properly tested by two independent examiners. The survey included 39 items distributed over 7 different pages. Participants were able to review their entries per page before moving on.

\subsection{Recruitment}

The target group of the survey consisted of individuals who actively played Wizards Unite 14 weeks after the release of the game. Non-players and former players were excluded from analyses in this paper because our focus is on the active gaming community of Wizards Unite after the release of the game, and comparing them with the Pokémon Go community. An initial question served as a screening question to identify active players of Wizards Unite. The sampling procedure was non-probabilistic, and respondents were selected based on their voluntary willingness to participate.

The weblink to the survey was posted in one private Facebook group ('RWTH Aachen University'; 22,500 members) and one public Facebook fan group called 'Harry Potter Wizards Unite-Deutsch Gruppe I MeinMMO' (about 2100 members). In total, 24,600 individuals potentially saw the link to our survey presented in their newsfeed or group on Facebook. The weblink to the survey was also posted in the German Wizards Unity Community 'Wizards Unite Forum' with 1130 members. This recruitment strategy is comparable to the recruitment for the former Pokémon Go survey (Rasche et al. 2017). In total, $\mathrm{n}=544$ unique individuals visited the website of our web-based survey. The identification of different individuals was performed using the Sosci Survey software based on Internet Protocol (IP) address and cookie function. In total, 119 of these 544 visitors started and finished the survey, and 25 started but discontinued completion of the survey. In total, 119 visitors fully participated in the survey and completed the whole questionnaire. After exclusion of former and non-players, 81 participants were selected for analysis. Due to data 
privacy settings, the recruitment channel name is unknown. The participation rate was thus $21.9 \%$, and the completion rate was $14.9 \%$.

\subsection{Statistical Analysis}

Data were analyzed using SPSS statistics software (version 24). To compare the two groups (players of Wizards Unite and players of Pokémon Go), we conducted t-tests for independent samples and $\chi^{2}$-statistics both at a significance level of 05 .

\section{Results}

\subsection{Sample}

In both surveys, $n=81$ participants were identified as active players of the game based on the screening question. Table 1 summarizes the demographic characteristics of active Wizards Unite and Pokémon Go players 14 weeks after the respective release of the game. The Wizards Unite players in our sample are significantly

Table 1 Participant demographics by game

\begin{tabular}{llll}
\hline $\begin{array}{l}\text { Active players of the } \\
\text { AR game }\end{array}$ & Wizards Unite $(\mathrm{n}=81)$ & Pokémon Go $(\mathrm{n}=81)$ & Significance \\
\hline Age (in years) & & & \\
Minimum & 21 & 19 & \\
Maximum & 62 & 60 & $t_{156}=3.31, P=.001$ \\
Mean (SD) & $40.31(10.6)$ & $34.9(9.8)$ & \\
Gender & & & $\chi_{2}^{2}=7.0, P=.03$ \\
Male & 38 & 54 & \\
Female & 42 & 27 & \\
Diverse & 1 & - & $\chi_{3}^{2}=1.2, P=.75$ \\
Education & & 4 & \\
Low level & 3 & 16 & \\
Average level & 15 & 55 & \\
High level & 53 & 6 & $\chi_{1}^{2}=.8, P=.36$ \\
Other & 10 & & \\
Environment & & 59 & $\chi_{1}^{2}=3.0, P=.09$ \\
Urban area & 53 & 22 & $\chi_{1}^{2}=.4, P=.053$ \\
Rural area & 27 & & $\chi_{1}^{2}=3.8, P=.05$ \\
Household & & 22 & $\chi_{1}^{2}=3.0, P=.09$ \\
Partner & 13 & 39 & \\
Family & 43 & 8 & \\
Shared flat & 2 & 13 & \\
Single & 22 & & \\
\hline & & &
\end{tabular}


older than the Pokémon Go players $\left(t_{156}=3.31, P=.001\right)$. For Wizards Unite, $42 \%$ of players are female, while for Pokémon Go, $27 \%$ are female $\left(\chi_{2}^{2}=7.0, P=.03\right)$. No significant differences are observed in terms of level of education, the living environment, and the household.

\subsection{Game Status and Usage Behavior}

Participants were asked whether they were a fan of Harry Potter independent of the game Wizards Unite. On a five-point scale ( $1=$ not a fan at all, 5=absolute fan), the mean for Wizards Unite players was 3.7 points (SD 1.1). Pokémon Go players were asked about their fan status of Pokémon by applying the same scale. The mean value for Pokémon Go players was 3.1 (SD 1.3) and there was a significant difference between the two groups of players $\left(\mathrm{t}_{160}=3.53, P=.001\right)$.

Table 2 summarizes further aspects of playing Wizard Unite and Pokémon Go as reported by the active players of both games. The mean duration of playing Wizards Unite reported by the Wizard Unite players in our sample was 3.1 months (SD .7) and the mean level in the game was 29.7 (SD 4.2). While the mean duration of use was significantly lower than reported by Pokémon Go players at the same point in time after the release of Pokémon Go $\left(t_{159}=3.31, P<.001\right)$, the mean level in the

Table 2 Game status and usage behavior of Wizards Unite and Pokémon Go

\begin{tabular}{|c|c|c|c|}
\hline \multirow[t]{2}{*}{ Game status and usage behavior } & \multicolumn{3}{|c|}{ Participants: active players of the AR game } \\
\hline & Wizards Unite $(\mathrm{n}=81)$ & Pokémon Go $(\mathrm{n}=81)$ & Significance \\
\hline $\begin{array}{l}\text { Duration of use (in months), mean } \\
\text { (SD) }\end{array}$ & $3.1(.7)$ & $3.9(.8)$ & $t_{159}=3.31, P<.001$ \\
\hline Level, mean (SD) & $29.7(4.2)$ & $27.0(3.9)$ & $t_{160}=4.16, P<.001$ \\
\hline $\begin{array}{l}\text { Duration played in the week after } \\
\text { installation (in hours), mean (SD) }\end{array}$ & $3.2(7.1)$ & $2.0(1.3)$ & $t_{82}=1.49, P=.14$ \\
\hline $\begin{array}{l}\text { Duration played last week (in } \\
\text { hours), mean (SD) }\end{array}$ & $2.3(5.1)$ & $1.7(1.3)$ & $t_{158}=.94, P=.35$ \\
\hline AR-environment only, \% (n/N) & $3(2 / 81)$ & $5(4 / 81)$ & $\chi_{1}^{2}=2.3, P=.32$ \\
\hline Virtual environment only, \% (n/N) & $89(72 / 81)$ & $91(74 / 81)$ & \\
\hline $\begin{array}{l}\text { Game mode depends on situation, } \\
\%(\mathrm{n} / \mathrm{N})\end{array}$ & $9(7 / 81)$ & $4(3 / 81)$ & \\
\hline In-app purchases, $\%(\mathrm{n} / \mathrm{N})$ & $53(43 / 81)$ & $57(46 / 81)$ & $\chi_{1}^{2}=.2, P=.64$ \\
\hline $\begin{array}{l}\text { In-app purchases }\left(\text { in } €^{\mathrm{b}}\right) \text {, mean } \\
\text { (SD) }\end{array}$ & $32.6(52.0)$ & $66.2(71.8)$ & $t_{82}=2.51, P=.013$ \\
\hline $\begin{array}{l}\text { Advice to play the game to others }{ }^{\mathrm{a}} \text {, } \\
\text { mean (SD) }\end{array}$ & $7.7(1.9)$ & $7.4(2.2)$ & $t_{160}=.95, P=.34$ \\
\hline $\begin{array}{l}\text { Being a Harry Potter/Pokémon fan, } \\
\text { mean }(\mathrm{SD})^{\mathrm{c}}\end{array}$ & $3.7(1.1)$ & $3.1(1.3)$ & $\mathrm{t}_{160}=3.53, P=.001$ \\
\hline
\end{tabular}

${ }^{\mathrm{a}}$ Measured on a scale from 1 to 10

bonly players who answered "yes" to In-App purchases

${ }^{\mathrm{c}}$ Measured on a five-point scale 
game was significantly higher $\left(t_{160}=4.16, P<.001\right)$. The mean duration played in the week before the survey (M 2.3) was lower than the mean duration played in the week after installation (M 3.2). This trend can be observed for both AR games and there are no significant differences (see Table 2). About half of the Wizards Unite players (53\%) reported having made in-app purchases on which on average 32.6 EUR were spent. The percentage of players who made in-app purchases was on a similar level for Pokémon Go players $\left(57 \% ; \chi_{1}^{2}=.2, P=.64\right)$ but the amount of money spent for Pokémon Go was significantly higher (66.2 EUR on average; $\left.t_{82}=2.51, P=.013\right)$. Recommendation to others to play the game was comparatively high for Wizards Unite and for Pokémon Go (7.7 and 7.4 on a 10-point scale).

The majority of Wizards Unite players (89\%) reported using the virtual game environment only and not using the AR-function of the game. A similar result was found for the Pokémon Go players, of which $91 \%$ reported using the virtual game environment only (see Table 2). The most important reasons for choosing the virtual game mode were the battery runtime of the smartphone and ease of use (see Fig. 1).

\subsection{Comparison of Motivations Inducing Players to Start Playing Wizards Unite or Pokémon Go}

On average, players of Wizards Unite and Pokémon Go reported two of the seven specific reasons why they started playing the game (Wizards Unite: M 2.2, SD .9; Pokémon Go: M 1.9, SD 1.1). There was no significant difference in the number of reasons reported by the two groups $\left(t_{160}=1.79, P=.08\right)$.

Curiosity and being a Harry Potter/Pokémon fan were important reasons why players started playing (see Table 3). Being a Harry Potter fan was reported significantly more often by Wizards Unite players, compared with the number of Pokémon Go players reporting being a Pokémon fan $\left(\chi_{1}^{2}=7.1, P=.008\right)$. By contrast,

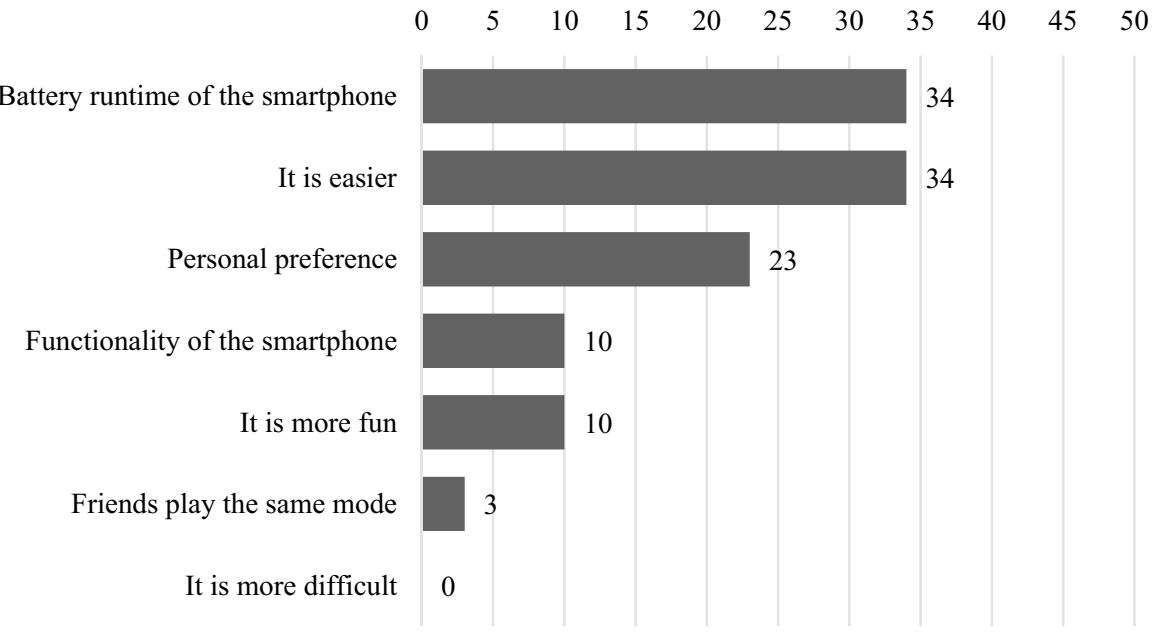

Fig. 1 Reasons for only using the virtual game environment in Wizards Unite (multiple answers possible), \%. active players of Wizards Unite who play virtual mode only $(n=72)$ 
Table 3 Motivations behind decision to start playing Wizards Unite and Pokémon Go (multiple answers allowed)

\begin{tabular}{llll}
\hline Motivation to start playing & \multicolumn{2}{l}{ AR game users } & Significance \\
\cline { 2 - 3 } & Wizards Unite, $\%(\mathrm{n} / \mathrm{N})$ & Pokémon Go, $\%(\mathrm{n} / \mathrm{N})$ & \\
\hline Curiosity & $57(46 / 81)$ & $68(55 / 81)$ & $\chi_{1}^{2}=2.1, P=.14$ \\
Being a Harry Potter/Pokémon fan & $61(49 / 81)$ & $40(32 / 81)$ & $\chi_{1}^{2}=7.1, P=.008$ \\
Media reports & $15(12 / 81)$ & $28(23 / 81)$ & $\chi_{1}^{2}=4.4, P=.036$ \\
Reports from friends & $10(8 / 81)$ & $27(22 / 81)$ & $\chi_{1}^{2}=8.0, P=.005$ \\
Everybody around me plays it & $3(2 / 81)$ & $14(11 / 81)$ & $\chi_{1}^{2}=6.8, P=.009$ \\
Being fascinated by the augmented & $11(9 / 81)$ & $6(5 / 81)$ & $\chi_{1}^{2}=1.3, P=.26$ \\
$\quad$ reality function & $49(40 / 81)$ & $-^{\mathrm{a}}$ & $-^{\mathrm{a}}$ \\
\hline \begin{tabular}{l} 
Because I played Pokémon Go \\
\hline
\end{tabular}
\end{tabular}

${ }^{\text {a}}$ No data available

Pokémon Go players were more motivated than Wizards Unite players by media reports $\left(\chi_{1}^{2}=4.4, P=.036\right)$, reports from friends $\left(\chi_{1}^{2}=8.0, P=.005\right)$, and seeing other people around them playing the game $\left(\chi_{1}^{2}=6.8, P=.009\right)$. The motivation provided by the AR function was not an important motivating factor in either group. About half of the Wizards Unite players (49\%) started to play the game because they had also played Pokémon Go (see Table 3).

\subsection{Comparison of Motivations Behind Continuing to Play Wizards Unite or Pokémon Go}

Players of Wizards Unite were asked whether reaching the next level motivated them to continue playing (10-point scale: $1=$ did not motivate at all, $10=$ highly motivated). The mean value for the group of Wizards Unite players was 6.9 (SD 2.3) points; the mean value for the group of Pokémon Go players was 7.1 points (SD $2.1)$. The two groups did not differ significantly $\left(\mathrm{t}_{160}=.75, \mathrm{P}=.45\right)$.

In open-ended questions, participants were able to indicate which other aspects of the game besides reaching the next level motivated them to continue playing. Table 4 reports the reasons given by Wizards Unite players and Pokémon Go players. Since the reasons were indicated in open-ended questions and coded afterwards, we compare these reasons only descriptively.

There was some overlap between the reasons reported by players of Wizards Unite and Pokémon Go. For example, both groups of players were motivated by the game mode of collecting/completing, by fun and curiosity, by being physically active, by the competition in the game, and by joint activities with family and friends. A higher number of Pokémon Go players were motivated by completing/collecting (41\% vs. $20 \%$ ). There were also specific motivational factors that were only reported by one group. Only players of Wizards Unite reported motivation due to events and quests and due to the story in the game. Among the 
Table 4 Motivation to continue playing Wizards Unite and Pokémon Go (multiple answers allowed)

\begin{tabular}{|c|c|c|}
\hline \multirow[t]{2}{*}{ Motivation to continue playing } & \multicolumn{2}{|l|}{ AR game users } \\
\hline & Wizards Unite, $\%(\mathrm{n} / \mathrm{N})$ & Pokémon Go, $\%(\mathrm{n} / \mathrm{N})$ \\
\hline Collecting/completing objects/pictures/the Pokédex ${ }^{\mathrm{a}}$ & $20(16 / 81)$ & $41(33 / 81)$ \\
\hline Events/quests $^{\mathrm{a}}$ & $16(13 / 81)$ & $-{ }^{\mathrm{b}}$ \\
\hline Fun or curiosity or recreation ${ }^{a}$ & $11(9 / 81)$ & $15(12 / 81)$ \\
\hline Being active or outside ${ }^{a}$ & $7(6 / 81)$ & $6(5 / 81)$ \\
\hline Competition/being the best ${ }^{\mathrm{a}}$ & $6(5 / 81)$ & $10(8 / 81)$ \\
\hline Story/evolution of the game ${ }^{a}$ & $6(5 / 81)$ & $-{ }^{\mathrm{b}}$ \\
\hline Joint activities with family and friends ${ }^{\mathrm{a}}$ & $5(4 / 81)$ & $6(5 / 81)$ \\
\hline Higher levels ${ }^{\mathrm{a}}$ & $4(3 / 81)$ & $4(3 / 81)$ \\
\hline Finding new or rare objects/Pokémon ${ }^{\mathrm{a}}$ & $-{ }^{\mathrm{b}}$ & $11(9 / 81)$ \\
\hline Updates or new generations $^{\mathrm{a}}$ & $-{ }^{\mathrm{b}}$ & $5(4 / 81)$ \\
\hline Incubating eggs ${ }^{\mathrm{a}}$ & $-{ }^{\mathrm{b}}$ & $3(2 / 81)$ \\
\hline Fighting in arenas $^{\mathrm{a}}$ & $-{ }^{\mathrm{b}}$ & $3(2 / 81)$ \\
\hline Nostalgia $^{\mathrm{a}}$ & $-{ }^{\mathrm{b}}$ & $3(2 / 81)$ \\
\hline
\end{tabular}

${ }^{\mathrm{a}}$ Answers to open-ended questions; coded for analysis, only answers mentioned by more than one person ${ }^{\mathrm{b}}$ Not mentioned in the survey

specific motivational factors reported by Pokémon Go players were nostalgia, updates, and finding rare objects/Pokémon (see Table 4).

\subsection{Comparison of Missing Functions Between Wizards Unite and Pokémon Go}

To further examine the aspects that motivate players to continue playing and any potential problems, we asked them about missing functions in the game. The missing functions differ to some extent between the Wizards Unite and Pokémon Go player groups (see Table 5).

The average number of missing functions did not differ significantly between the groups $\left(t_{153}=1.50, P=.14\right)$. However, we identified significant differences for specific missing functions between the two games. More collectibles (Foundables/Pokémons) in the neighborhood $\left(\chi_{1}^{2}=20.0, P<.001\right)$, direct fights against others $\left(\chi_{1}^{2}=8.2, P=.004\right)$, more points of interest (Greenhouses/Pokéstops) $\left(\chi_{1}^{2}=24.5, P<.001\right)$, and more updates $\left(\chi_{1}^{2}=14.4, P<.001\right)$ were mentioned more often by Pokémon Go players than by Wizards Unite players. No significant differences were observed in terms of the possibility to exchange items (e.g. Pokémons) for more Fortresses/Gyms, or in terms of better AR function. More Pokémon Go players cited more collectibles in the neighborhood and more points of interest as missing functions (see Table 5). 
Table 5 Missing functions in Wizards Unite and Pokémon Go (multiple answers allowed)

\begin{tabular}{|c|c|c|c|}
\hline \multirow[t]{2}{*}{ Missing functions } & \multicolumn{2}{|l|}{ AR game users } & \multirow[t]{2}{*}{ Significance } \\
\hline & Wizards Unite, $\%(\mathrm{n} / \mathrm{N})$ & Pokémon Go, \% (n/N) & \\
\hline Mean of number of functions (SD) & $2.5(1.3)$ & $2.8(1.6)$ & $t_{153}=1.50, P=.14$ \\
\hline No missing functions & $9(7 / 81)$ & $4(3 / 81)$ & $\chi_{1}^{2}=1.7, P=.19$ \\
\hline $\begin{array}{l}\text { More Foundables/Pokémon in my } \\
\text { neighborhood }\end{array}$ & $24(19 / 81)$ & $58(47 / 81)$ & $\chi_{1}^{2}=20.0, P<.001$ \\
\hline Exchanging items/Pokémon & $62(50 / 81)$ & $56(45 / 81)$ & $\chi_{1}^{2}=.6, P=.43$ \\
\hline Direct fights against others & $32(26 / 81)$ & $54(44 / 81)$ & $\chi_{1}^{2}=8.2, P=.004$ \\
\hline More Greenhouses/Pokéstops & $10(8 / 81)$ & $44(36 / 81)$ & $\chi_{1}^{2}=24.5, P<.001$ \\
\hline More updates & $12(10 / 81)$ & $38(31 / 81)$ & $\chi_{1}^{2}=14.4, P<.001$ \\
\hline More Fortresses/Gyms & $37(30 / 81)$ & $26(21 / 81)$ & $\chi_{1}^{2}=2.3, P=.13$ \\
\hline Better augmented reality & $3(2 / 81)$ & $3(2 / 81)$ & $\chi_{1}^{2}=0, P=1.0$ \\
\hline Play for the dark side & $16(13 / 81)$ & $-^{\mathrm{a}}$ & $-^{\mathrm{a}}$ \\
\hline
\end{tabular}

${ }^{a}$ No data available

\section{Discussion}

As exemplified by the success of Pokémon Go, AR-based smartphone games are loved by millions of people worldwide, and have caught the attention of the media and academic researchers. With reference to findings on a survey on Pokémon Go, this paper reports on motivational aspects behind gameplay of a title with a very similar game mechanics but a different theme, Wizards Unite. We compared the two games in terms of players' perceptions and motivations in relation to starting and continuing to play the game.

\subsection{Target Groups and Players' Motivations}

The demographic characteristics of the players of the two games differ to some extent. For example, a higher proportion of the players of Wizards Unite are female, and the players of Wizards Unite were generally older than the players of Pokémon Go. The high proportion of female players was also identified in another study on Wizards Unite (Laato et al. 2020). While this might be an indication of the two games being aimed at different target groups, it should be mentioned that $49 \%$ of Wizards Unite players have also played Pokémon Go. Therefore, we were able to recruit players who had not played Pokémon Go, in contrast with other studies (e.g. Laato et al. 2020).

With reference to the ways in which Wizards Unite and Pokémon Go are played, players of Wizards Unite on average reported a lower total time duration of playing, but a higher level reached in the game. In other words, when people start to play Wizards Unite, they seem to be more active and they reach higher levels in a shorter time. In our study sample, Wizards Unite players often played together with family and friends, and they exerted a rather high level of physical activity. The social 
component is among the most important success factors of current pervasive games (Arango-López et al. 2017). This provides the basis for possible training effects of AR-based games, as already described by Laato et al. (2019). At the same time, less money was spent for in-app purchases in Wizards Unite than in Pokémon Go.

\subsubsection{Motivation to Start Playing}

The high level of publicity surrounding Pokémon Go was also visible in the motivations which induced players to start playing. Pokémon Go players were motivated by media reports and friends, and also by sensing that everybody around them played the game, in contrast with Wizards Unite players. On the other hand, more Wizards Unite players reported being a Harry Potter fan, compared with the number of Pokémon Go players reporting being a Pokémon fan. This might be an indication of the large Harry Potter fanbase, and that Harry Potter fans were attracted to the game.

\subsubsection{Motivation to Continue Playing and Missing Functions}

Both groups reported being motivated by fun and curiosity, physical activity, by the competition in the game, and by joint activities with family and friends. However, collecting was more motivating among players of Pokémon Go than those of Wizards Unite. This can potentially be explained by the story behind the game. The main goal in Pokémon Go is to "catch "em all", whereas Wizards Unite builds on a more complex story behind the game (Laato et al. 2020). Thus, one of the main motivational aspects behind playing Wizards Unite was the complex game story within the already known game structure. Players collect magical ingredients, brew potions, fight against wizards and much more. This becomes also obvious in the missing functions reported by the players of both games. Pokémon Go players reported more Pokémon in the neighborhood most often, whereas Wizards Unite players reported the possibility for exchanging items most often (Rasche et al. 2017). It needs to be mentioned at this point that Wizards Unite does possess some of the relevant missing functions which appeared in the first release of Pokémon Go (e.g. social interaction).

\subsection{Implications for Future AR-Based Games}

\subsubsection{Relevance of the AR Game Concept}

Among both groups of players, the AR function of the game was used by almost none of the participants (based on their self-reported answers). The AR functionality was also not reported as an important motivating factor behind their decision to start playing one of the games either. Furthermore, only a small proportion of the players wanted improved AR functionality. This leads to the suggestion that the implementation of AR in the game does not seem to be an important feature as far as active players are concerned, but that other aspects are more important. The reasons given by Wizards Unite players for choosing the virtual mode over the AR-based mode 
were mostly practical, such as battery runtime and the easier virtual game mode. The lack of relevance of the AR mode may also be due to the fact that games use the AR features only to a minimal extent and apply basic AR mechanics. The future potential of AR in the context of gaming but also in other contexts, such as education, need to be addressed (Daniela and Lytras 2019; Laato et al. 2019) and combinations of AR with game-based learning seem to be a promising field (Pellas et al. 2019).

Further research should also deepen our understanding of older adults playing AR-based games. Within both samples represented in this study, older adults were present. Nevertheless, older players tends to be a demographic group which is less addressed by the gaming industry, and so a digital divide between younger and older adults persists (Francis et al. 2019). By finding an interesting game theme, it might be possible to facilitate the positive effects of AR and locations-based games also for older adults (Schlomann et al. 2019).

\subsubsection{Relevance of Location-Based Gaming}

To connect to the previous point, it seems that the AR game concept is not the main motivation for players. As reported by the players, their expectations with both games relate more to the experience of playing in real-world settings, and the connection between virtual with real-life movements.

One reason for the larger success of Pokémon Go might be that the game mode of collecting does not necessarily fit the world of J.K. Rowling's Harry Potter and Wizards Unite. This was also shown in the reasons for continuing to play, as well as in relation to the missing functions, reported by the players in our sample. Walking around in a real-world neighborhood and collecting objects, creatures, and people for Wizards Unite does not engender quite the same feelings of excitement and accomplishment as walking around and collecting Pokémons. It seems like Pokémon Go makes the player feel like a "real" Pokémon trainer, while Wizards Unite doesn't make them feel like a "real" wizard.

However, our results also show that a complex story like Wizards Unite appeals to many players and should be implemented in location-based game concepts. One of the strengths of Wizards Unite compared to Pokémon Go in terms of long-term motivation could be the story that is created. It seems important that this is based on open world game-concepts in which players can actively explore their neighborhood.

\subsubsection{Relevance of the Game Theme}

Considering the similarities between games as reported at the beginning of this article, a key difference between both games is the game theme. While the game concept of Pokémon Go was relatively simple ("catch "em all"), Wizards Unite tells a more complex story. This could be seen as addressing a different market, in this case Harry Potter fans, or in providing a new theme (edition) to the community playing location-based gaming.

Being a fan (of Harry Potter/Pokémon) independent of the game is another important motivational factor. Active players of Wizards Unite in our sample reported to 
play the game mostly independently of media reports and reports from friends. On the other hand, curiosity was a further relevant motivating factor behind the decision to start playing, for the players of both games. This reason was even more important for Wizards Unite players than for Pokémon Go players. Given that the mean age is around 40 years in both samples, this might also be an indication that both games address individuals from the same generations that have known the themes of the games since the 1990 s.

Furthermore, hunting and collecting 'Pokémons' might feel more exciting and compelling, compared to filling books or pictures with items. Furthermore, players reported higher motivations to continue due to events and quests and the story of the game implemented in Pokémon Go. For a long-term engagement it is relevant to create meaningful games. In this way, Wizards Unite might be more successful in terms of motivating players in the long run, compared to Pokémon Go. The backstory and game narrative have also been identified as important factors of engagement and motivation for serious games (Ravyse et al. 2017).

Another aspect important in terms of future AR-based games is a well-defined and specific target group for the game. Our results show that technical features and the AR-functionality seem to be less important than the game theme itself. Developers should ask themselves who might be interested in the game theme and, if possible, built on well-known game themes.

\subsubsection{Migration of Players Between Games}

About half of the sample of Wizards Unite players also reported playing Pokémon Go. In view of this, to the best of our knowledge, we might be the first researchers who are investigating migrating gamers as well as new gamers. By contrast, Laato et al. (2020) recruited nearly a 100\%-sample of players of both games.

If players are playing both games, we interpret this as a general interest in the game concept, i.e. the geocaching concept and aspects of social interaction, that are, however, largely independent of the AR-functionality. The combination of digital games and physical activity (see also "Wii Fit" for Wii and more recently "Ring Fit Adventure" for Nintendo Switch) captures the spirit of the age. The connection with outdoor activities in Wizards Unite and Pokémon Go, and the option of mixing virtual objects with the real-world setting, are another attractive add-ons (ArangoLópez et al. 2017). The new gamers are more likely to be recruited based on the fact that these are Harry Potter fans who are drawn to the newest element of fan fiction. Future studies should provide more insights about the migration between different games in the field of location-based gaming, as this is already occurring with classic gaming systems as Microsoft Xbox or Sony PlayStation.

\section{Limitations}

This study has several limitations related to its methodological design as well as the reported results. The open web-based study results are not representative of all game players due to regional recruiting via Facebook. Although the sample of Facebook 
users is adequate in terms of representative population characteristics, biases are still possible (Rife et al. 2016). Due to the open web-based recruitment, no inferences can be made about the usage ratings and sociodemographic distribution of the general user group of Wizards Unite, especially as this web-based survey was conducted in German.

Furthermore, this study was conducted 14 weeks after the initial release of Wizards Unite in Germany. Thus, it is comparable with the study of Pokémon Go players performed in 2016 (Rasche et al. 2017). Nevertheless, this study only reveals initial motivational aspects for active users of Wizards Unite due to the lack of a long-term perspective.

Pokémon Go was the first commercially successful game in this game category and unique in its gameplay. This should be mentioned as a limitation, as Wizards Unite is similar to Pokémon Go in terms of its gameplay. Although curiosity for the game was named as one of the main motivating factors behind the decision to start playing, the lack of novelty in Wizards Unite might have influenced the results of this survey.

Another limitation is that between both games and thus both surveys there is a time delay of about three years, which might have influenced the general perspective on such games as well as on the gameplay. Although in both surveys, the initial versions of the two games were tested, making a comparison is difficult. Wizards Unite lacked a lot of the social interaction functionalities that have made Pokémon Go popular since its initial release. This might have influenced the players' motivation to start playing Wizards Unite as it was not perceived as "social" as Pokémon Go. Nevertheless, less social interaction was already a demand within the Pokémon Go survey, an aspect which is more apparent in the different game.

\section{Conclusions}

By applying an exploratory approach, we have compared two commercially available AR and location-based games. To the best of our knowledge, this is the first study that explicitly and systematically compares the motivation of active users of Wizards Unite and Pokémon Go users with a survey that is designed in a parallel manner across the two games. We were able to determine aspects which motivated users to start playing Wizards Unite and we were also able to derive possible longterm success factors of Wizards Unite. Further insights which could inform developers' designs of long-lasting serious games and which have implications for future AR-based games were derived from the results for players of both games. Our findings show the importance of social components and the connection to movement in real-world settings. Along with the mental connection of real buildings with virtual content, it is possible to increase users' interest in current location-based games.

Acknowledgements The authors thank So-Sci Survey for their support by licensing software free of charge, Sheridan Patterson (University of Oklahoma, OK, USA) for support in language editing, and Moritz Richter (RWTH Aachen, Germany) for support in programming the questionnaire and data 
preparation. This publication is part of the research project "TECH4AGE," financed by the Federal Ministry of Education and Research (BMBF, under Grant No. 16SV7111) and promoted by VDI/VDE Innovation + Technik GmbH.

Author's Contribution All authors contributed to the study conception and design. Material preparation, data collection and analysis were performed by all authors. The first draft of the manuscript was written by Anna Schlomann and all authors commented on previous versions of the manuscript. All authors read and approved the final manuscript.

Funding Open Access funding enabled and organized by Projekt DEAL. No funding was received for this study.

\section{Compliance with Ethical Standards}

Conflict of interest The authors declare that they have no competing interests.

Informed Consent Informed consent was obtained from all of the participants included in the study.

Open Access This article is licensed under a Creative Commons Attribution 4.0 International License, which permits use, sharing, adaptation, distribution and reproduction in any medium or format, as long as you give appropriate credit to the original author(s) and the source, provide a link to the Creative Commons licence, and indicate if changes were made. The images or other third party material in this article are included in the article's Creative Commons licence, unless indicated otherwise in a credit line to the material. If material is not included in the article's Creative Commons licence and your intended use is not permitted by statutory regulation or exceeds the permitted use, you will need to obtain permission directly from the copyright holder. To view a copy of this licence, visit http://creativecommons.org/licen ses/by/4.0/.

\section{References}

Althoff, T., White, R. W., \& Horvitz, E. (2016). Influence of Pokémon Go on physical activity: Study and implications. Journal of medical Internet research, 18(12), e315. https://doi.org/10.2196/ jmir.6759.

Arango-López, J., Gallardo, J., Gutiérrez, F. L., Cerezo, E., Amengual, E., \& Valera, R. (2017, September). Pervasive games: Giving a meaning based on the player experience. In Proceedings of the XVIII international conference on human computer interaction (pp. 1-4). https://doi. org/10.1145/3123818.3123832.

Ayers, J. W., Leas, E. C., Dredze, M., Allem, J.-P., Grabowski, J. G., \& Hill, L. (2016). Pokémon GO-A new distraction for drivers and pedestrians. JAMA Internal Medicine, 176(12), 1865-1866. https:// doi.org/10.1001/jamainternmed.2016.6274.

Best, S. J., \& Krueger, B. S. (2004). Internet data collection. London: SAGE.

Daniela, L., \& Lytras, M. D. (2019). Editorial: Themed issue on enhanced educational experience in virtual and augmented reality. Virtual Reality, 23(4), 325-327. https://doi.org/10.1007/s10055-01900383-z.

Ewell, P. J., Quist, M. C., Øverup, C. S., Watkins, H., \& Guadagno, R. E. (2020). Catching more than pocket monsters: Pokémon Go's social and psychological effects on players. The Journal of Social Psychology, 160(2), 131-136. https://doi.org/10.1080/00224545.2019.1629867.

Francis, J., Ball, C., Kadylak, T., \& Cotten, S. R. (2019). Aging in the digital age: Conceptualizing technology adoption and digital inequalities. In B. B. Neves \& F. Vetere (Eds.), Ageing and digital technology (pp. 35-49). Singapore: Springer Singapore. https://doi.org/10.1007/978-981-13-3693-5_3.

Hamari, J., Malik, A., Koski, J., \& Johri, A. (2019). Uses and gratifications of Pokémon Go: Why do people play mobile location-based augmented reality games? International Journal of Human-Computer Interaction, 35(9), 804-819. https://doi.org/10.1080/10447318.2018.1497115. 
Handrahan, M. (2019). Harry Potter: Wizards Unite's first month revenue lags far behind Pokémon Go. Retrieved March 12, 2020 from https:/www.gamesindustry.biz/articles/2019-07-24-harry-potte r-wizards-unites-first-month-revenue-lags-far-behind-pok-mon-go.

Hino, K., Asami, Y., \& Lee, J. S. (2019). Step counts of middle-aged and elderly adults for 10 months before and after the release of Pokémon GO in Yokohama, Japan. Journal of Medical Internet Research, 21(2), e10724. https://doi.org/10.2196/10724.

Howe, K. B., Suharlim, C., Ueda, P., et al. (2016). Gotta catch'em all! Pokémon GO and physical activity among young adults: Difference in differences study. BMJ. https://doi.org/10.1136/bmj.i6270.

Knöll, M., Dutz, T., Hardy, S., \& Göbel, S. (2014). Urban exergames: How architects and serious gaming researchers collaborate on the design of digital games that make you move. In M. Ma, L. C. Jain, \& P. Anderson (Eds.), Virtual, augmented reality and serious games for healthcare 1 (pp. 191-207). Heidelberg: Springer. https://doi.org/10.1007/978-3-642-54816-1_11.

Laato, S., Hyrynsalmi, S., Rauti, S., Islam, A. K. M. N., \& Laine, T. H. (2020). Location-based games as exergames-From Pokémon to the wizarding world. IJSG, 7(1), 79-95. https://doi.org/10.17083 /ijsg.v7i1.337.

Laato, S., Pietarinen, T., Rauti, S., Paloheimo, M., Inaba, N., \& Sutinen, E. (2019). A review of location-based games: Do they all support exercise, social interaction and cartographical training?. In CSEDU (1) (pp. 616-627).

LeBlanc, A. G., \& Chaput, J.-P. (2017). Pokémon Go: A game changer for the physical inactivity crisis? Preventive Medicine, 101, 235-237. https://doi.org/10.1016/j.ypmed.2016.11.012.

Leiner, D. J. (2014). SoSci Survey Version 2.5. 00-i (Computer Software) 2014. Retrieved January 20, 2020.

McLaughlin, L., Prithwijit, D., Kate, F., et al. (2019). Learning from Pokémon GO and preparing for Potter: The impact of augmented reality video games on adolescent physical activity. International Journal of Sports and Exercise Medicine, 5(1), 118. https://doi.org/10.23937/2469-5718/1510118.

Paavilainen, J., Korhonen, H., Alha, K., Stenros, J., Koskinen, E., \& Mayra, F. (2017). The Pokémon GO experience. In G. Mark, S. Fussell, C. Lampe, M. C. Schraefel, J. P. Hourcade, C. Appert, et al. (Eds.), Proceedings of the 2017 CHI conference on human factors in computing systems-CHI ' 17. New York, NY: ACM Press (pp. 2493-2498). https://doi.org/10.1145/3025453.3025871.

Pellas, N., Fotaris, P., Kazanidis, I., \& Wells, D. (2019). Augmenting the learning experience in primary and secondary school education: A systematic review of recent trends in augmented reality gamebased learning. Virtual Reality, 23(4), 329-346. https://doi.org/10.1007/s10055-018-0347-2.

Rasche, P., Schlomann, A., \& Mertens, A. (2017). Who is still playing Pokémon Go? A web-based survey. JMIR Serious Games, 5(2), e7. https://doi.org/10.2196/games.7197.

Ravyse, W. S., Seugnet Blignaut, A., Leendertz, V., \& Woolner, A. (2017). Success factors for serious games to enhance learning: A systematic review. Virtual Reality, 21(1), 31-58. https://doi. org/10.1007/s10055-016-0298-4.

Rife, S. C., Cate, K. L., Kosinski, M., \& Stillwell, D. (2016). Participant recruitment and data collection through Facebook: The role of personality factors. International Journal of Social Research Methodology, 19(1), 69-83. https://doi.org/10.1080/13645579.2014.957069.

Schlomann, A., Rasche, P., Seifert, A., Schäfer, K., Wille, M., Bröhl, C., et al. (2019). Augmented reality games for health promotion in old age. In V. Geroimenko (Ed.), Augmented reality games II (pp. 159-177). Cham: Springer International Publishing. https://doi.org/10.1007/978-3-030-15620-6_7.

Serino, M., Cordrey, K., McLaughlin, L., \& Milanaik, R. L. (2016). Pokémon Go and augmented virtual reality games: A cautionary commentary for parents and pediatricians. Current Opinion in Pediatrics, 28(5), 673-677. https://doi.org/10.1097/MOP.0000000000000409.

Topolovec-Vranic, J., \& Natarajan, K. (2016). The use of social media in recruitment for medical research studies: A scoping review. Journal of medical Internet research, 18(11), e286. https://doi. org/10.2196/jmir.5698.

Warner Bros. Entertainment. (2020). Harry Potter: Wizards Unite Software. Retrieved March 10, 2020 from https://www.harrypotterwizardsunite.com.

Wizarding World Digital. (2020). Wizarding World-The official home of Harry Potter. Retrieved March 10, 2020 from https://www.wizardingworld.com. 